\title{
DETERMINATION OF LOCOMOTIVE DERAILMENT STABILITY CONDITIONS IN EMERGENCY COLLISIONS
}

\author{
Institute of Technical Mechanics \\ of the National Academy of Sciences of Ukraine and the State Space Agency of Ukraine \\ 15 Leshko-Popel St., 49005,Dnipro, Ukraine; e-mail: dep7@ukr.net
}

This paper discusses the behavior of a locomotive in its collision with a movable obstacle on the railway track. Movable obstacles of different masses were considered: a freight train, a similar locomotive, and an empty freight car. Initially, the obstacle was motionless, and after the collision it began to move along the track. The aim of this study is to determine conditions for locomotive wheelset stability against derailment in the emergency situation under consideration. .

To solve this problem, use was made of the authors' mathematical model of spatial vibrations of a six-axle locomotive equipped with a passive safety system and anticlimbing devices and the authors' software that allows one to investigate dynamic processes occurring both in the normal operation of railway vehicle and in emergencies.

First, we considered accidents for the case where the forces occurring in the collision of a moving vehicle with an obstacle act only in the longitudinal direction, which coincides with the track axis. In this case, the longitudinal axis of the locomotive body remains parallel to that of the track, and the locomotive wheelsets do not derail. This is possible only if the track condition is ideal. When a locomotive moves along a real track with irregularities of different types, vehicle vibrations are set up, which leads to the occurrence of a time-varying angle of rotation of the locomotive body about the vertical axis in the horizontal plane. In such a situation, a collision with an obstacle produces not only longitudinal forces, but also lateral forces of interaction of the colliding vehicles. In its turn, this results in an increase in the lateral wheel/rail interaction forces, which greatly affect the derailment stability of the locomotive wheelsets.

The calculations showed the locomotive wheel derailment probability increases with the mass of the obstacle and the locomotive speed at the collision instant. The derailment stability of a locomotive equipped with a passive safety system in emergency collisions also depends significantly on the railway track technical state. The higher is the level of rail irregularities, the higher is the derailment probability.

Keymords emergency, dynamic index, locomotive, mathematical simulation, derailment.

1. Myamlin S. V., Naumenko N. Yu., Markova O. M. , Kovtun E. N., Malyi V. V. Assessment of the dynamic performance of a six-axle locomotive (in Russian). Nauka i Progress Transporta : Vestnik DIITa. 2015. No. 3 (57). Pp. 186 - 198.

2. Naumenko N. Yu., Khizha I. Yu. Simulation of the interaction of passenger train vehicles equipped with a passive safety system in an emergency collision with an obstacle (in Russian). Nauka i Progress Transporta : Vestnik DIITa. 2015. - No. 4 (58). Pp. $163-174$.

3. Naumenko N. Yu., Sobolevska M. B., Khizha I. Yu. Assessment of the dynamic loading of a reference train with a passive safety system in tis collisions with an identical train and a freight car (in Russian). Nauka i Progress Transporta : Vestnik DIITa. 2015. - No. 4 (58). Pp. 163 - 174.

4. Codes for the calculation and design of $1520 \mathrm{~mm}$ railway cars (non-self-propelled) (in Russian. Moscow: GosNIIV - VNIIZhT, 1996. - 319 pp.

5. Technical instructions for railway track condition assessment from track measurement car data and train operation safety assurance in the case of departures from the track maintenance standards (in Ukrainian). TsP-0267 : Approved by Ukrzaliznytsia Order No. 033-Ts of February 1, 2012 / Ministry of Infrastructure of Ukraine, State Administration of Railway Transport of Ukraine, Ukrzaliznytsia, Directorate General of Track Facilities : developed by Rybkin V. V., Patlasov O. M. - Kyiv. Poligrafservis, 2012. - 46 pp. 